\title{
Brain Interactions between Extinction and Reconsolidation in the Treatment of Fear Memories
}

\author{
Dagieli Sartor $^{1}$, Natália Gindri Fiorenza ${ }^{1}$, Jociane de Carvalho Myskiw ${ }^{1}$, Iván Izquierdo ${ }^{1,2}$ \\ ${ }^{1}$ Centro de Memória, Instituto do Cérebro, Pontifical Catholic University of Rio Grande do Sul, Porto Alegre, Brazil; ${ }^{2}$ National \\ Institute of Translational Neuroscience, National Research Council of Brazil and Memory Center, Brain Institute, Pontifical Catholic \\ University of Rio Grande do Sul, Porto Alegre, Brazil. \\ Email: Izquier@terra.com.br
}

Received July $4^{\text {th }}$, 2011; revised July 25 ${ }^{\text {th }}$, 2011; accepted August $6^{\text {th }}, 2011$.

\begin{abstract}
Memory traces become labile at the time of retrieval, and this initiates two protein synthesis-dependent processes in the brain: extinction, which inhibits their further retrieval, and reconsolidation, which may enhance retrieval or change the memory's content. Extinction may itself suffer reconsolidation. Interactions between these processes may be applied to the treatment of fear memories, such as those underlying the post-traumatic stress disorder.
\end{abstract}

Keywords: Memory, Extinction Learning, Reconsolidation, Fear Memories

\section{Introduction}

Memories can be modified in many ways after they are consolidated. The two best known and most widely studied ways are extinction and reconsolidation, which change memories quantitatively and, in the case of reconsolidation, also in part qualitatively. Of course, the mere quantitative alteration of any given memory or group of memories can modify cognition very extensively: The great philosopher Norberto Bobbio (1909-2004) said that "we are what we remember" [1]. It is impossible to be what we do not remember; we live, think, perceive and make plans for the future based on memories. And if we change what we remember, we certainly will change what we are.

The nonreinforced retrieval of long-tem memories reactivates the previously consolidated traces of those memories and puts them in a labile state, in which they may undergo two opposite protein synthesis-dependent processes: extinction [1,2] and reconsolidation [1,3-5]. Extinction was originally described by Pavlov over a century ago [2]. Reconsolidation has been recognized relatively recently [1,3]. Both processes are triggered during the first retrieval session after the original consolidation of memories [5-8], and have been described in a very large number of species and learning situations. Reconsolidation mechanisms apparently are activated somewhat earlier than extinction processes in the central nervous system of crabs [9]. It would be impractical if reconsolidation mechanisms were activated after extincttion has already been initiated because by then the extinction process would have already begun to take its toll [1,11].

Extinction consists of the inhibition of retrieval of previously consolidated memories $[1,2,4,6]$, and is widely used in the treatment of fearsome or otherwise disagreeable memories, such as those underlying post-traumatic stress disorder or other disagreeable and fearsome memories $[3,4,6]$. The fading away of memories not yet consolidated, such as those that last only a few minutes or hours, (i.e., short-term memories) may be viewed as shortterm extinction [12], but it is not clear whether it is part of the same phenomenon. Short-term memories may just fade away because they are not sustained and underlain or substantiated by brain protein synthesis [13]. Reconsolidation reaffirms memories which could otherwise be lost $[3,6,9]$ and may allow incorporation of additional information into them $[10,12]$ which is, by the way, commonplace in retrieval sessions [12]; actually, multitrial learning consists of new learnings on top of retrievals, repeatedly. Such learning is indeed the one most used for educational purposes all over the world. Extinction is a form of learning $[1,4,13,14]$, whereas reconsolidation is 
instead a property of retrieval [4] which might or might not involve additional learning [10,12]. Extinction is directly observable $[1,2,7,17]$; reconsolidation must be inferred from observations that post-retrieval treatments such as protein synthesis inhibition in amygdale [15] or hippocampus [16,17] reduce retrieval in a subsequent session.

Extinction is not to be confused with forgetting: responses can recover spontaneously if the extinction trials are delayed, or return in full if just one reinforcement is given $[1,2,14]$, which means that they remain encoded in the brain throughout. Reconsolidation is not a recapitulation or a repetition of consolidation: the time course of both processes is different, and so are several of the brain structures and molecular processes involved [4,16-18].

Knowledge about extinction and reconsolidation has accumulated in recent years, but their possible interacttions have been less studied. Recent findings suggest that these interactions could be of clinical significance in the treatment of fear memories, such as those of post-traumatic stress disorder.

Abundant evidence shows that both extinction and reconsolidation are initiated by retrieval $[7,8]$. Indeed, this is particularly evident in extinction, whose early phases in the test session that follows the last reinforced trial have been much better worked out than those of reconsolidation, particularly in the hippocampus [13,18-20]. Several of the biochemical changes that underlie retrieval in this structure, such as the activation of protein kinase A and extracellularly regulated kinases [20] may at the same time be the basis for the biochemical basis of extinction [18-20]. Both extinction and reconsolidation are pharmacologically affected by a variety of drugs given into the hippocampus [20], the basolateral amygdale [15], the entorhinal cortex $[5,6]$ and/or the ventromedial prefrontal cortex [4] immediately after retrieval $[4,6,10]$. While extinction can take place any time after the original learning (days, months, years [2]) and regardless of how many times the animals have been exposed to it before [23], reconsolidation can only be obtained if the retrieval session that triggers it occurs very shortly after the original training (a few hours [21] or at most a few days [22]). Susceptibility of reconsolidation to protein synthesis inhibitors given into the amygdala or hippocampus decreases as the time between training and recall increases [21], and so does the reconsolidating effect of retrieval. As will be seen, this property of retrieval has been recently put to use in the design of a new technique to promote a better extinction.

\section{The Use of Extinction in the Treatment of Fear-Motivated Learning}

In the first half of the past century the most studied forms of fear-motivated behaviors were the phobic states, and the prevailing explanation of these states was Pierre Janet's theory of a constitutional lowering of brain energy, somehow related to hysteria [24]. Panic was believed to be also closely related to phobias. In 1909, Freud described the case of Little Hans, a 5-year old boy with a strong oedipal complex and an intense fear and rejection of his father, from whom he feared castration. This marked for Freud a turning point in his studies and thinking about fear-motivated disorders [24]. Phobias were until then seen as the major and prototypical fearmotivated disorder. Over the years, the family of disorders generated by fear learning began to be recognized as much larger than just the phobias and today post-traumatic stress disorder (PTSD) is justly seen as the most serious and incapacitating member of that family [25].

Note that in this very brief historical survey we made reference to Pierre Janet's idea of fear motivated behaveiors as related to hysteria, and to Freud's early belief that such behaviors derived from the symbolic fear of castration. Gains or losses of brain energy, hysteria and symbolic fear of castration are seldom if ever mentioned in today's more biologically oriented Psychiatry or Neuroscience articles or books, except for historical reasons. Actually, hysteria and symbolic fear of castration have all but disappeared as clinical entities.

In the first years of the 20th century, panic began to be differentiated from the phobias. Until then, both were pooled together: it was customary to say that exposure to certain objects or situations caused panic. From the 1960's through the 1980's pharmacological treatments differentiated them further: panic responds readily to benzodiazepines and phobias do not. Over the years, two major World Wars and a long succession of other catastrophes made the post-traumatic stress disorder (PTSD) recognizable as the main and most serious disease of the family of fear-motivated disorders. It is very significant that the front cover of one the most recent major books on PTSD [25] features a picture of soldiers at war; war is in some countries a major cause of PTSD. In others it is earthquakes, tsunamis, floods, landslides or other natural or man-made disasters or personal sufferings.

At some point back in the 1920's Freud and his disciple of the times, Sandor Frenczi found it hardly possible to treat even phobias with psychoanalytic techniques, let alone more serious fear-motivated syndromes, and turned to Pavlovian extinction, which Freud called "habituation". They applied it with success from the start to the treatment of phobias [25].

In the last 30 years, PTSD was recognized as the most serious and as a very prevalent fear-motivated disorder. Pavlovian extinction began to be applied with success to the treatment of PTSD $[4,6,10]$. The clinical procedure 
involves exposure of the patient to the feared object or context without any danger while the therapist comforts the client in order to reduce anxiety. It has become known by a variety of different names (exposure, flooding, desensitization, etc.), because of the strong resistance of most North American and some European Psychologists and Psychiatrists to the adoption of Pavlovian terminology. Freud himself called it "habituation", which in Pavlovian terminology and in Neuroscience as a whole means something else [1,2]. Habituation is the waning of an unconditioned response with repetition, whereas extinction is the waning of a conditioned response. Freud was a contemporary of Pavlov and saw in him a competitor in Psychological or Psychiatric theory and terminology. Today, in turn, many psychiatrists and psychologists reject Freudian concepts and terminology, and a large number of them belong to a school advocating Cognitive Therapy as an approach to the treatment of mental disturbances quite different from Psychoanalysis, be it Freudian or non-Freudian. They consider "exposure" therapy as belonging to the realm of Cognitive Therapy. Perhaps inadvertently Freud himself laid the foundation of Cognitive Therapy back in the 1920's when he introduced extinction for the treatment of phobias; even he thought it better to use it under a different name.

\section{Why, unlike in Most Other Psychiatric Disorders, Drugs are Little Used to Treat PTSD or Phobias}

The possibility of erasing memories, rather than just inhibiting their expression, has been entertained since McGaugh and coworkers first showed drug-induced inhibition of memory consolidation by posttraining treatments in the 1950's [26] and Gold, Izquierdo, Bohus and their coworkers described the inhibition of retrieval by pre-test treatments in later years [12]. Posttraining "amnesic" treatments, however, actually prevent or cancel the on-going recording of memories rather than cause a real amnesia; humans who receive them perceive them as amnestic because they cannot interpret a short-lived loss of recording otherwise [1]. While it is of course certainly possible to cancel memories in humans by posttraining or pre-test treatments, both procedures are seriously hampered by their time-locked nature. For example, it has been shown that the posttraining administration of $\beta$ noradrenergic receptor antagonists like propranolol can cause "retrograde amnesia" for many if not all kinds of memory, first in rodents $[1,26]$ and more recently in humans [27]. The same happens with general anesthetics [28], such as sevofluorane [29]. However, it is obviously impractical to use any of these treatments, since people do not walk about with propranolol or sevoflurane in their pockets to use immediately after acquiring a trau- matic memory, which is when these treatments act [11]. Likewise, many treatments are very effective in blocking retrieval, sometimes permanently [12] when given shortly before a retention test session. Perhaps physiologically the most important pre-test amnestic treatments are cortisol and other glucocorticoids [31-33]. Actually, their effect has been shown to be caused by an interference with $\beta$-noradrenergic receptors in the basolateral amygdale [34] and very probably in hippocampus and other cortical regions [35] which mediate retrieval and are sensitive to their hormones [36]. But, then, people simply do not carry corticoids to use in anticipation of a traumatic episode that is yet to come. Actually, many episodes are traumatic because they happen by surprise.

Further, many consider that erasing a memory, no matter how bad that memory may be is ethically improper (see [5] for a discussion of this point); even though that possibility so far has proven to be largely theoretical for the practical reasons discussed in the preceding paragraph (i.e., the timing of the drug administrations). So far, in effect, the selective erasure of one or a few given memories has been only a subject of fiction. It can be counterargued that there is no ethical reason that can justify preserving the memory of a rape or of a session of torture if it can be effectively eliminated [1,5].

Therefore, neither posttraining nor pre-test pharmacological treatments are of much practical value in alleviating PTSD or related syndromes, including the phobias. Since no other drug effects are known that may act to inhibit traumatic or otherwise unwanted memories at times other than the strict posttraining or pre-test periods $[1,12]$, there really is no appropriate way to treat fearmotivated syndromes with drugs, aside from panic attacks. These do pertain, however, to a different class of anxiety disorders, inasmuch as, contrary to phobias or certainly PTSD, they are not linked to any traceable memory of a given stimulus or event. Panic happens on its own, usually unpredictably, and can be treated with benzodiazepines or other anxiolytic compounds once it starts or, in those cases in which it recurs preferentially around a given hour of the day, before that hour, daily; neither is the case with PTSD or phobias.

\section{Interactions between Extinction and Reconsolidation, and Their Possible Application to PTSD Therapy}

The widely accepted use of extinction for the treatment of fear-motivated disorders has generated much research recently on how it can be enhanced by making use of what we already know about its interaction with mere retrieval and with reconsolidation. LeDoux, Monfils and their collaborators recently submitted rats to a retrieval session of fear learning shortly after acquisition and, 
once the memory of the fear was labilized, exposed them to formal extinction of the task [21]. The intercalated "extra" retrieval session was of course a session of extinction, actually the first of a series; but it was given within the $6 \mathrm{~h}$ "reconsolidation" window, a time after the original training in which the memory trace was labilized. This pre-exposure or "reminder" procedure facilitated extinction. The data suggest that this procedure should be useful to enhance the therapeutic effect of extinction in fear-motivated tasks, which has been used for years in the treatment of the posttraumatic stress disorder [3,5,9]. Since this treatment is not fail-safe $[3,9,21]$. and the obvious alternative, the pharmacological inhibition of reconsolidation is difficult, if at all possible, in humans [3, $5,16,17]$, the "trick" proposed by LeDoux and coworkers of interposing an isolated retrieval session at a time of memory labilization before the formal extinction procedure in order to increase the susceptibility of the memory to extinction seems very sound. Before the notion of labilization by retrieval took hold $[3,15]$, of course the extra trial presented before formal extinction would have been viewed as just one more extinction trial; i.e., actually the first of the extinction series $[1,18]$.

In another paper LeDoux, Monfils, Phelps and coworkers updated an originally fearful memory with nonaversive information during the reconsolidation window in humans and successfully erased the former for at least one year, without affecting other memories [37]. Actually, this may be viewed as one form of inducing extincttion; in extinction, the original response is actually superseded by another response, namely, that of specifically inhibiting the original response $[1,5,14,15]$. Both in the memory update and in the pre-exposure procedure an obvious requisite is that the labilization session is carried out shortly after acquisition of the memory, which in real-life post-traumatic stress is of course not always possible. Actually, the memory update described by this last experiment [37] is only the second known clear-cut instance of memory updating at the time of reconsolidation. The two are in humans [10,37].

Recently, García de la Torre et al. [38] and Rossato et al. [17] reported that extinction itself, being as it is one form of learning, can be subjected to reconsolidation in at least two different tasks in rats. Both groups showed that the infusion of anisomycin into selected brain structures right after the first extinction trial of a series hindered extinction performance in subsequent trials. García de la Torre et al. [38] studied conditioned taste aversion and infused the protein synthesis inhibitor into the insular cortex, which governs both the consolidation and the extinction of that behavior. Rossato et al. [17] studied inhibitory avoidance and infused the anisomycin into the dorsal hippocampus. Each of these brain areas is specifi- cally involved both in the consolidation and in the extinction of the respective behaviors. This suggests the possibility of yet another form of improving the extinction of fear memories, indicates an important behavioral property of extinction that had not been previously described [2-9], its reconsolidation, and is in line with the procedures advocated by LeDoux and coworkers for inhibition of the recall of fear.

It must be borne in mind, however, that recent studies have shown that, at least for the inhibitory avoidance task, the array of brain structures involved in consolidation are not necessarily the same that are involved in extinction [39,40], which is important for understanding the physicology of the two processes. Since evidence also suggests that the areas involved in the consolidation and reconsolidation of several memories may not be the same [16] (see above), there is ample possibility for interactions between all these brain processes mediated by a diversity of brain connections, and there might be differences between interactions between retrieval with or with or without updating, for example; or after a little or after a lot of extinction.

\section{Possible and Impossible Mechanisms of Extinction-Reconsolidation Interaction}

Above it was commented that evidence indicates a role for signaling pathway and RNA and protein synthesis in the hippocampus [18] and the amygdale [15] in extinction and reconsolidation. Further, evidence indicates a similar role or roles for the entorhinal cortex [41], and of neuronal firing [42] and protein synthesis [43] in ventromedial prefrontal cortex, at least in the generation of extinction. fMRI studies in humans support the hypothesis of a major role for the ventromedial prefrontal cortex in conjunction with amygdala and hippocampus in the regulation of fear retrieval and extinction [44]. Some electrophysiological and structural details are beginning to become known, such as the cell types of the lateral amygdala that are involved in these functions [45]. Functional magnetic resonance studies also point to specific relations between the limbic areas and the ventromedial prefrontal cortex in extinction [46].

Some fMRI studies have led to the hypothesis that PTSD may indeed occur preferentially in subjects whose ventromedial prefrontal cortex is thinner and smaller than the norm [47], a possibility that requires further investigation.

Aside from brain structures, some brain neurohumoral systems have been proposed or shown to play a role in extinction. Of these, the best studied is perhaps the endocannabinoid system, located mainly in the hippocampus One possibility raised by several groups in recent years is that extinction may be mediated by the release 
and action of endogenous cannabinoids in the hippocampus. The hippocampus contains endocannabinoids. These are small lipids that bind to local cannabinoid receptors and caus a number of effects; among them, extinction [54]; in fact, Marsicano, Lutz and their coworkers [54] and others [55] have attributed to them a major role in the regulation of that process. The evidence stands quite solid and largely uncontested [5,6]. However, extinction being a major form of learning and as such quite complex can certainly not be attributed to a single factor in the brain. There is other evidence commented upon above and elsewhere [4,6] that other brain areas and other neurohumoral systems ( $\beta$-adrenergic synapses, corticoids, etc.) must also be involved and each play a major role.

In addition to these limbic brain structures, a wealth of evidence points to a key role of the ventromedial prefrontal cortex in extinction $[4,41,42]$, but not on reconsolidation. In extinction in humans, this role is suggested by functional magnetic resonance (fMRI) observations during extinction; reconsolidation studies using fMRI have either not been performed or are unreliable. In animals, the role of specific molecular mechanisms in the two structures has been rather widely explored in recent years using localized intra-hippocampal and/or intraamygdala microinfusions of protein synthesis inhibitors and/or of drugs known to either stimulate or inhibit selected enzymes of signaling pathways [5,6,18-20,34], or some neurotransmitter antagonists [35].

\section{Drugs as Adjuncts to Extinction Therapy in the Treatment of PTSD or the Fear Disorders.}

The impossibility or implausibility of using drugs to treat PTSD or phobias makes the use of extinction therapy not only desirable, but also mandatory [3-5].

Quite another thing is to use drugs as adjuncts to extinction-based therapy. This was tried over the years with a number of drugs, from the already mentioned corticoids [31] to gonadal hormones [51] to the $\beta$-blockers discussed above, sometimes in (unsuccessful) combinations with other drugs or in different schedules [52,53]. Promising results were reported with corticoids (see [30]), despite side effects, and with the agonist at the glycine site of glutamate NMDA receptors, D-cycloserine [31]. D-cycloserine was once a mildly effective tuberculostatic agent, and so its general pharmacology has been relatively well known for decades. The side effects are well known, and they are not many $[54,55]$. The fact that systemic D-cycloserine has any effect at all on human extinction is in a way surprising, since glutamate NMDA receptors in hippocampus and several other laces not only mediate extinction [20] but also, and importantly, other forms or phases of learning [1].

So far, no other treatment has been proven better than extinction, particularly with the pre-exposure "tricks" envisaged by LeDoux and his associates [21,37]. Conceivably the application of appropriate reconsolidation procedures to standard extinction could prove useful [17].

\section{Conclusions}

Recent advances in the understanding of the interactions between retrieval-dependent processes (labilization of the trace, reconsolidation, extinction) have produced potentially useful additions to the time-honored use of extinction (often under the name of exposure therapy $[3,5,9]$ ) in the treatment of fear memories. The term "exposure" is used by many as a synonym or a disguise of the old Pavlovian term, extinction [1,2,3,5]. Logistic reasons (it is usually impossible both to predict when a traumatic event will actually happen, or to bring the drug along at all times in case one such event may happen) have prevented the development of any appropriate medication for the treatment or prevention of PTSD and related syndromes. An alternative, to be explored in the next few years, appear to be the use of some drugs as adjuncts to extinction therapy. D-cycloserine is the most promising such drug so far.

\section{REFERENCES}

[1] I. Izquierdo, “Memoria,” 2nd Edition, Porto Alegre, ArtMed, 2011.

[2] I. P. Pavlov, “Conditioned Reflexes,” Dover, New York, 1956.

[3] S. J. Sara, "Strengthening the Shaky Trace through Retrieval,” Nature Review Neuroscience, Vol. 1, No. 3, 2000, pp. 212-213. doi:10.1038/35044575

[4] G. J. Quirk, D. Paré, R. Richardson, C. Herry, M. H. Monfils, D. Schiller and A. Vicentic, "Erasing fear Memories with Extinction Training," The Journal of Neuroscience, Vol. 30, No. 45, 2010, pp. 14993-14997. doi:10.1523/JNEUROSCI.4268-10.2010

[5] I. Izquierdo, L. R. Bevilaqua, R. H. Lima, J. H. Clarke and M. Cammarota, "Extinction Learning: Neurological Features, Therapeutic Applications, and Effect of Aging," Future Neurology, Vol. 3, 2008, pp. 133-141. doi:10.2217/14796708.3.2.133

[6] L. M. Bevilaqua, M. Cammarota, J. H. Medina, I. Izquierdo, "Extinction" In: L. Sher and A. Vilens, Eds., Neurobiology of Posttraumatic Stress Disorder, Nova Publishers, New York, 2010, pp. 309-330.

[7] M. Cammarota, L. R. Bevilaqua, D. M. Barros, M. R. M. Vianna, L. A. Izquierdo and J. H. Medina, "Retrieval and the Extinction of Memory," Cellular and Molecular Neurobiology, Vol. 256, 2002, pp. 465-474.

[8] L. M. Perez-Cuesta, Y. Hepp, M. E. Pedreira and H. 
Maldonado, "Extinction Memory in the Crab Chasmagnathus: Recovery Protocols and Effects of Multi-Trial Extinction Training," Learning and Memory, Vol. 14, No. 1, 2007, pp. 101-108.doi:10.1101/lm.413507

[9] W. S. Beckett, "Post-Traumatic Stress Disorder," The New England Journal of Medicine, Vol. 346, No. 2, 2002. pp. 130-132. doi:10.1056/NEJM200201103460213

[10] C. Forcato, M. L. Rodríguez, M. E. Pedreira and H. Maldonado, "Reconsolidation in Humans Opens up Declarative Memory to the Entrance of New Information," Neurobiology of Learning and Memory, Vol. 93, No. 1, 2010, pp. 77-84.

[11] M. Cammarota, L. R. Bevilaqua, J. I. Rossato, M. R. Ramírez, J. H. Medina and I. Izquierdo, "Relationship between Short- and Long-Term Memory and Short- and Long-Term Extinction," Neurobiology of Learning and Memory, Vol. 84, No. 1, 2005, pp. 25-32. doi:10.1016/j.nlm.2005.03.002

[12] I. Izquierdo, "Endogenous State Dependency: Memory Depends on the Relation between the Neurohumoral and Hormonal States Present after Training and at the Time of Testing," In: G. Lynch, J. L. McGaugh and N. M. Weinberger, Eds., Neurobiology of Learning and Memory, Guilford Press, New York, 1984, pp. 333-350.

[13] L. M. Igaz, M. R. Vianna, J. H. Medina and I. Izquierdo, "Two Time Periods of Hippocampal Rna Synthesis Are Required for Memory Consolidation of Fear-Motivated Learning,” Journal of Neuroscience, Vol. 22, No. 3, 2002, pp. 6781-6789.

[14] R. A. Rescorla, “Spontaneous Recovery,” Learning and Memory, Vol. 11, 2004, pp. 501-509. doi:10.1101/lm.77504

[15] K. Nader, G. E. Schafe and J. E. LeDoux, "Fear Memories Require Protein Synthesis in the Amygdala for Reconsolidation after Retrieval,” Nature, Vol. 416, 2000, pp. 722-726.

[16] J. I. Rossato, L. R. Bevilaqua, J. H. Medina, I. Izquierdo and M. Cammarota, "Retrieval Induces HippocampusDependent Reconsolidation of Spatial Memory,” Learning and Memory, Vol. 13, 2006, pp. 431-441. doi:10.1101/lm.315206

[17] J. I. Rossato, L. R. Bevilaqua, I. Izquierdo, J. H. Medina and M. Cammarota, "Retrieval Induces Reconsolidation of Fear Extinction Memory," Proceeding of the National Academy of Science of the United States of America, Vol. 107, No. 50, 2010, pp. 21801-21805.

[18] M. R. M. Vianna, G. Szapiro, J. L. McGaugh, J. H. Medina and I. Izquierdo, "Retrieval of Memory for FearMotivated Training Initiates Extinction Requiring Protein Synthesis in the Rat Hippocampus," Proceeding of the National Academy of Science of the United States of America, Vol. 98, No. 21, 2001, pp. 12251-12254.

[19] G. Szapiro, L. A. Izquierdo, M. Alonso, D. M. Barros, G. Paratcha, P.G. Ardenghi, P. Pereira, J. H. Medina and I. Izquierdo, "Participation of Hippocampal Metabotropic Glutamate Receptors, Protein Kinase A and Mitogen-Activated Protein Kinases in Memory Retrieval," Neurosci- ence, Vol. 99, No. 1, 2000, pp. 1-5.

[20] G. Szapiro, M. R. M. Vianna, J. L. McGaugh, J. H. Medina and I. Izquierdo, "The Role of NMDA Glutamate Receptors, PKA, MAPK and CAMKII in the Hippocampus in the Extinction of Conditioned Fear," Hippocampus, Vol. 13, 2003, pp. 53-58.

[21] M. H. Monfils, K. K. Cowansage, E. Klann and J. E. LeDoux, "Extinction-Reconsolidation Boundaries: Key to Persistent Attenuation of Fear Memories,” Science, Vol. 324, No. 5929, 2009, pp. 951-955.

[22] M. H. Milekic and C. M. Alberini, “Temporally Graded Requirement for Protein Synthesis Following Memory Reactivation,” Neuron, Vol. 36, No. 3, 2002, pp. 531-535.

[23] I. Izquierdo, W. Wyrwicka, G. Sierra and J. P. Segundo, "Etablissement de Reflexes Conditionnés de Trace Pendant le Sommeil Naturel Chez le Chat. Actual," Neurophysiology, Vol. 6, 1965, pp. 277-296.

[24] P. Janet, “The Major Symptoms of Hysteria,” Macmillan, New York, 1906.

[25] J. C. Nemiah, "Comprehensive Textbook of Psychiatry," In: H. I. Kaplan and B. J. Sadock, Eds., Williams and Wilkins, Baltimore, 1985, pp. 894-942.

[26] J. L. McGaugh, “A Century of Consolidation,” Science, Vol. 287, No. 5451, 2000, pp. 248-351.

[27] S. P. Orr, M. R. Milad, L. J. Metzger, N. B. Lasko, M. W. Gilbertson and R. K. Pitman, "Effects of $\beta$-Receptor Blockade, PTSD Diagnosis, and Explicit Threat on the Extinction and Retention of an Aversively Conditioned Response,” Biological Psychology, Vol. 73, No. 3, 2006, pp. 262-271. doi:10.1016/j.biopsycho.2006.05.001

[28] M. J. Herz, C. E. Spooner and A. A. Cherkin, "EEG and Multiple Unit Responses to the Amnes Sic Agent Flurothyl in Chicks," Proceedings of the Western Pharmacology Society, Vol. 12, 1969, pp. 62-64.

[29] M. T. Alkire, R. Gruver, J. Miller, J. R. McReynolds, E. L. Hahn and L. Cahill, "Neuroimaging Analysis of an Anesthetic Gas that Blocks Human Emotional Memory," Proceeding of the National Academy of Science of the United States of America, Vol. 115, 2008, pp. 17221727.

[30] D. J. de Quervain, D. Bentz, T. Michael, O. C. Bolt, B. K. Wiederhold, J. Margraf and F. H. Wilhelm, "Glucocorticoids Enhance Extinction-Based Psychotherapy," Proceeding of the National Academy of Science of the United States of America, Vol. 108, No. 16, 2011, pp. 66216625.

[31] D. J. de Quervain, "Glucocorticoid-Induced Inhibition of Memory Retrieval: Implications for Posttraumatic Stress Disorder," Annals of the New York Academy of Science, Vol. 1071, 2006, pp. 216-220. doi:10.1196/annals.1364.016

[32] A. Aerni, R. Traber, C. Hock, B. Roozendaal, G. Schelling, A. Papassotiropoulos, R. M. Nitsch, U. Schnyder and D. de Quervain, "Low-Dose Cortisol for Symptoms of Posttraumatic Stress Disorder," The American Journal of Psychiatry, Vol. 161, No. 8, 2004, pp. 1488-1490. doi:10.1176/appi.ajp.161.8.1488

[33] D. J. de Quervain, K. Henke, A. Aerni, V. Treyer, J. L. 
McGaugh, T. Berthold, R. M. Nitsch, A. Buck, B. Roozendaal and C. Hock, "Glucocorticoid-Induced Impairment of Declarative Memory Retrieval Is Associated with Reduced Blood Flow in the Medial Temporal Lobe," The European Journal of Neuroscience, Vol. 17, No. 6, 2003, pp. 1296-1302. doi:10.1046/j.1460-9568.2003.02542.x

[34] M. Davis, K. M. Myers, J. Chhatwal and K. J. Ressler, "Pharmacological Treatments that Facilitate Extinction of Fear: Relevance to Psychotherapy," The Journal of the American Society for Experimental NeuroTherapeutics, Vol. 3, No. 1, 2006, pp. 82-96.

[35] D. M. Barros, L. A. Izquierdo, T. Mello e Souza, P. Ardenghi, P. Pereira, J. H. Medina and I. Izquierdo, "Molecular Signaling Pathways in the Cerebral Cortex Are Required for Retrieval of One-Trial Avoidance Learning in Rats,” Behavioural Brain Research, Vol. 114, No. 200, pp. 183-192.

[36] D. M. Barros, T. Mello e Souza, T. De David, H. Choi, A. Aguzzoli, C. Madche, P. Ardenghi, J. H. Medina and I. Izquierdo, "Simultaneous Modulation of Retrieval by Dopaminergic D(1), Beta-Noradrenergic, Serotonergic$1 \mathrm{~A}$ and Cholinergic Muscarinic Receptors in Cortical Structures of the Rat," Behavioural Brain Research, Vol. 124, 2001, pp. 1-7. doi:10.1016/S0166-4328(01)00208-X

[37] D. Schiller, M. H. Monfils, C. M. Raio, D. C. Johnson, J. E. LeDoux and E. A. Phelps, "Preventing the Return of Fear in Humans Using Reconsolidation Update Mechanisms," Nature, Vol. 463, No. 7277, 2010, pp. 49-53.

[38] P. Garcia de la Torre, C. J. Rodríguez-Ortiz, I. Balderas and F. Bermúdez-Rattoni, "Differential Participation of Temporal Structures in the Consolidation and Reconsolidation of Taste Aversion Extinction," The European Journal of Neuroscience, Vol. 32, No. 6, 2010, pp. 10181023.

[39] R. H. Lima, J. I. Rossato, C. R. Furini, L. R. Bevilaqua, I. Izquierdo and M. Cammarota, "Infusion of Protein Synthesis Inhibitors in the Entorhinal Cortex Blocks Consolidation but Not Reconsolidation of Object Recognition Memory," Neurobiology of Learning and Memory, Vol. 91, No. 4, 2009, pp. 466-472. doi:10.1016/j.nlm.2008.12.009

[40] J. C. Myskiw, N. G. Fiorenza, L. A. Izquierdo and I. Izquierdo, "Molecular Mechanisms in Hippocampus and Basolateral Amygdala but Not in Parietal or Cingulate Cortex Are Involved in Extinction of One-Trial Avoidance Learning," Neurobiology of Learning and Memory, Vol. 94, No. 2, 2010, pp. 285-291. doi:10.1016/j.nlm.2010.06.007

[41] L. R. Bevilaqua, J. S. Bonini, J. I. Rossatto, L. A. Izquierdo, M. Cammarota and I. Izquierdo, "The Entorhinal Cortex Plays a Role in Extinction,” Neurobiology of Learning and Memory, Vol. 85, No. 2, 2006, pp. 192197. doi:10.1016/j.nlm.2005.10.001

[42] M. R. Milad and G. J. Quirk, "Neurons in Medial Prefrontal Cortex Signal Memory for Fear Extinction,” $\mathrm{Na}$ ture, Vol. 420, No. 6911, 2002, pp. 7-74.

[43] E. Santini, H. Ge, K. Ren, S. Peña de Ortiz and G. J. Quirk, "Consolidation of Fear Extinction Requires Pro- tein Synthesis in the Medial Prefrontal Cortex,” Journal of Neuroscience, Vol. 24, No. 25, 2004, pp. 5704-5710. doi:10.1523/JNEUROSCI.0786-04.2004

[44] M. R. Delgado, K. I. Nearing, J. E. Ledoux and E. A. Phelps, "Neural Circuitry Underlying the Regulation of Conditioned Fear and Its Relation to Extinction,” Neuron, Vol. 59, No. 5, 2008, pp. 829-838.

[45] E. Likhtik, D. Popa, J. Apergis-Schoute, G. A. Fidacaro and D. Paré, "Amygdala Intercalated Neurons Are Required for Expression of Fear Extinction,” Nature, Vol. 454, No. 7204, 2008, pp. 642-645.

[46] M. R. Milad, C. I. Wright, S. P. Orr, R. K. Pitman, G. J. Quirk and S. L. Rauch, "Recall of Fear Extinction in Humans Activates the Ventromedial Prefrontal Cortex And Hippocampus in Concert,” Biological Psychology, Vol. 62, No. 5, 2007, pp. 446-454. doi:10.1016/j.biopsych.2006.10.011

[47] M. R. Milad, B. T. Quinn, R. K. Pitman, S. P. Orr, B. Fischl and S. L. Rauch, "Thickness of Ventromedial Prefrontal Cortex in Humans Is Correlated with Extinction Memory," Proceeding of the National Academy of Science of the United States of America, Vol. 102, No. 30, 2005, pp. 10706-10711.

[48] R. K. Pitman and D. L. Delahanty, "Conceptually Driven Pharmacologic Approaches to Acute Trauma,” CNS Spectrums, Vol. 10, No. 2, 2005, pp. 99-106.

[49] R. K. Pitman, K. M. Sanders, R. M. Zusman, A. R. Healy, F. Cheema, N. B. Lasko, L. Cahill and S. P. Orr, "Pilot study of Secondary Prevention of Posttraumatic Stress Disorder with Propranolol,” Biology Psychiatry, Vol. 51, No. 2, 2002, pp. 189-51192. doi:10.1016/S0006-3223(01)01279-3

[50] B. D. Heifets and P. E. Castillo, "Endocannabinoid Signaling and Long-Term Synaptic Plasticity," Annual Review of Physiology, Vol. 71, 2009, pp. 283-306. doi:10.1146/annurev.physiol.010908.163149

[51] G. Marsicano and B. Lutz, "Neuromodulatory Functions of the Endocannabinoid System," Journal of Endocrinological Investigation, Vol. 29, Supplement 3, 2006, pp. 27-46.

[52] M. R. Milad, M. A. Zeidan, A. Contero, R. K. Pitman, A. Klibanski, S. L. Rauch and J. M. Goldstein, "The Influence of Gonadal Hormones on Conditioned Fear Extinction in Healthy Humans," Neuroscience, Vol. 168, No. 3, 2010, pp. 653-658.

[53] K. J. Ressler, B. O. Rothbaum, L. Tannenbaum, P. Anderson, K. Graap, E. Zimand, L. Hodges and M. Davis, "Cognitive Enhancers as Adjuncts to Psychotherapy: Use of D-Cycloserine in Phobic Individuals to Facilitate Extinction of Fear," Archives of General Psychiatry, Vol. 61, No. 11, 2004, pp. 1136-1144. doi:10.1001/archpsyc.61.11.1136

[54] M. Davis, K. Ressler, B. O. Rothbaum and R. Richardson, "Effects of D-Cycloserine on Extinction: Translation from Preclinical to Clinical Work,” Biological Psychiatry, Vol. 60, No. 4, 2006, pp. 369-375. doi:10.1016/j.biopsych.2006.03.084 